\title{
Is the Quality of Life, Functionality and Podiatric Evaluation of Adolescents with Clubfoot Treated by Ponseti Method Worse than that of Other Adolescents?
}

\section{Ey Batlle Ana Maria ${ }^{1 *}$, Moral Benitez Helena ${ }^{2}$, Vinyals Rodriguez Marta $^{1}$, Perez Palma Laura ${ }^{2}$ and Míguez Gonzalez Paula ${ }^{1}$}

${ }^{1}$ Equipo Ponseti Dra. Anna Ey, Clínica Diagonal, Barcelona, Spain

${ }^{2}$ Departamento de Podologia Pediatrica y Podología Clínica, Facultad de

Podología (UB), Barcelona, Spain

*Corresponding Author: Ey Batlle Ana Maria, Equipo Ponseti Dra. Anna Ey, Clínica

Diagonal, Barcelona, Spain.
Received: July 26, 2021

Published: August 09, 2021

(C) All rights are reserved by Ey Batlle Ana

Maria., et al.

\begin{abstract}
Introduction: The Congenital talipes equinovarus (CTEV), also known as clubfoot has an incidence of 1 or 2 per 1.000 live births in Europe. Nowadays, the predominant treatment is Ponseti Method, which includes manipulation and casting.

Objective: To analyses and compare with a control group, the quality of life, function and podiatric measures of the patient with CTEV treated with the Ponseti Method 18 years after treatment.

Materials and Methods: A comparative study of 12 adolescent CTEV patients (19 feet) and a Control. Inclusion criteria in CTEV group: Having being treated with Ponseti method, no surgical releases and more than 18 y.o. Laaveg - Ponseti score and SF - 36 are used for quality of life and functionality. The maximum pronation test, the supination resistance test, Lunge's test and FPI used as podiatric assessment

Results: Everyone got an evaluation between excellent and good in the Laaveg - Ponseti test. In the SF - 36 questionnaire the results obtained were similar between the groups. but the podiatric evaluation was clearly different. Only 4 from the 12 CTEV patients had been treated by a podiatrist.

Discussion: The study shows similar results between both groups, Concerning the Laaveg - Ponseti test both groups display similar results and in the SF - 36 test the results showed a slight improvement in the Clubfoot group, however the results are not statistically significant. The podiatric evaluation results are different between both groups. Despite function of clubfeet after Ponseti Method in adolescents is very good we can detect mild structural changes with podiatric tests.

Conclusion: In terms on functionality and quality of life there are no significative differences between clubfeet and control cases but podiatric evaluation shows statistical differences between both groups.

Level of Evidence: II Or 2b (Oxford Level of evidence).

Keywords: Clubfoot; Adolescent; Ponseti Method; Function; Quality of Life; Podiatry
\end{abstract}

\section{Introduction}

The Congenital talipes equinovarus (CTEV) is one of the most common musculoskeletal deformities and it affects approximately
1 or 2 per 1.000 live births in Europe [1,2]. Nevertheless, its incidence increases considerably in developing countries and it can be a cause of social isolation. This situation has lead to the

Citation: Ey Batlle Ana Maria., et al. "Is the Quality of Life, Functionality and Podiatric Evaluation of Adolescents with Clubfoot Treated by Ponseti Method Worse than that of Other Adolescents?". Acta Scientific Orthopaedics 4.9 (2021): 23-30. 
development of international cooperative programs in order to perform a correct treatment [3].

Fifty per cent of the cases of CTEV affects both feet and its level of incidence is greater in the male gender, with a ratio male to female of 3 to 4/1; yet despite these observations the correlation between gender and clubfoot side has not been established to date [3-5].

Nearly $20 \%$ of the cases are due to associated malformations, chromosomal abnormalities and other syndromes, such as arthrogryposis and myelomeningocele. However, approximately $80 \%$ of the cases are idiopathic; there are many hypotheses concerning aetiology and therefore a multifactorial origin is accepted [6,7]. At this moment, genetic causes are being researched and certain variations in HOXA9, TPM1, TPM2 and PITX1 have been identified. These variations are involved in muscle development and muscle function $[4,6,8,9]$.

There are many assessment scoring systems to classify CTEV according to severity, such as DiMeglio and Pirani scores. Recent studies have exposed that there is no correlation between severity and the complexity of the treatment, and so the prognosis of the scoring systems is being questioned [10-12].

Nowadays, the Ponseti Method is the Gold Standard for the treatment of congenital clubfoot. This treatment has been described by Dr. Ignacio Ponseti in 1963 at the University of Iowa [4,13].

The Ponseti Method is a detailed method of manipulation and casting. The number of casts required for clubfoot correction depends on the specialist, but it is usually between 4 and 5 . Afterwards, the equinus position of the foot requires a percutaneous Achilles tenotomy in more than $90 \%$ of cases preferably under local anaesthetic. After the tenotomy a final cast is applied, and it will last almost 2 - 3 weeks. Finally, patients start using abduction braces where the foot affected must be in $60^{\circ}$ of abduction if it is a bilateral case or in $70^{\circ}$ if there is a unilateral foot affected while the normal foot will be in $30^{\circ}$ of external rotation. In the first place, braces must to be worn 23 hours per day during a three month period after which their use will gradually be reduced. Afterwards, when the child starts walking, it must be used only at night for at least 4 - 5 years [4,13-15].
The functionality of the CTEV treated by the Ponseti Method can be analysed with the Laaveg-Ponseti test, published in 1980 by Dr Ponseti (10 questions easy to translate) [16]. And the quality of life can be evaluated with SF.36 questionnaire that was used in multiple papers and is validated in the Spanish language.

\section{Materials and Methods}

The study has got the ethical approval of the institution and all participants in the study have signed the informed consent documentation.

A comparative and descriptive study was carried out between two groups:

1. Group of clubfoot: The criteria for inclusion were patients older than 18 years old, patients initially treated with the Ponseti Method and patients without associated pathology while the criteria for exclusion were patients younger than 18 years old, patients treated by aggressive surgical intervention not described by the Ponseti Method and patients with associated pathology.

2. The control group is formed by 12 adolescents, over 18 years of age, 4 female $(33.3 \%)$ and 8 males $(66,67 \%)$.

All the CTEV patients were selected by a Paediatric Orthopaedic International Team, world renowned in the Ponseti treatment of clubfoot. The clubfoot group were all born between 1997 and 2000. All data regarding the age at the beginning of treatment, the affected side, the number of casts, the initial tenotomy or anterior tibial tendon transfer required was collected.

The assessment of A total of 12 patients with 19 clubfeet was included. Of this group 5 (41.67\%) were female and 7 (58.33\%) were male. For the control group, a total of 12 young adults (24 feet) were evaluated, 4 (33.33\%) were female and 8 (66.67\%) were male. The table 1 includes the detailed information.

Functionality was measured by the Laaveg-Ponseti test. The Laaveg-Ponseti scale makes an integral evaluation of function and deformity and range of motion, it has to be filled in by the professional, ranking from 0 to 100 points [16].

Quality of life was evaluated using the SF-36 questionnaires. The SF-36 was designed by Ware., et al. [17] and it comprises 36 questions that can evaluate the patient's physical and mental

Citation: Ey Batlle Ana Maria., et al. "Is the Quality of Life, Functionality and Podiatric Evaluation of Adolescents with Clubfoot Treated by Ponseti Method Worse than that of Other Adolescents?". Acta Scientific Orthopaedics 4.9 (2021): 23-30. 
health. The questionnaire is divided into 8 subscales: general health, physical functionality, role limitations due to emotional problems, role limitations due to physical functionality, social functioning, pain, vitality and mental health. It was required to be filled by the patient. Each subscale has a range 0 - 100 (optimal) [18-21]. In addition, a control group was selected with ages between 18 and 22, without any associated pathology, in which the SF-36 questionnaire was performed.

Also, a podiatric evaluation was added including:

- Maximum pronation test (Figure 1).

- Supination resistance test (Figure 2).

- $\quad$ The Lunge's test (Figure 3).

- Foot Posture Index (FPI) (Figure 4).
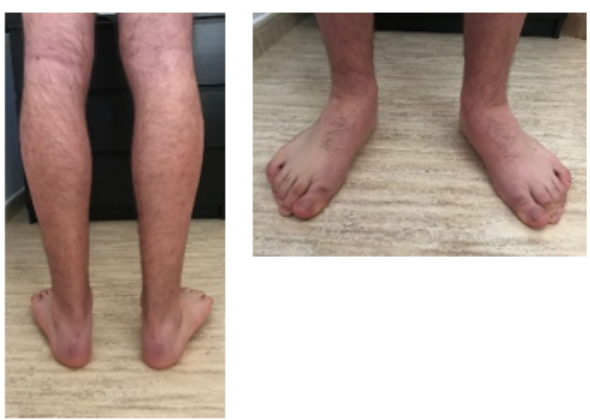

Figure 1: Maximum pronation test.

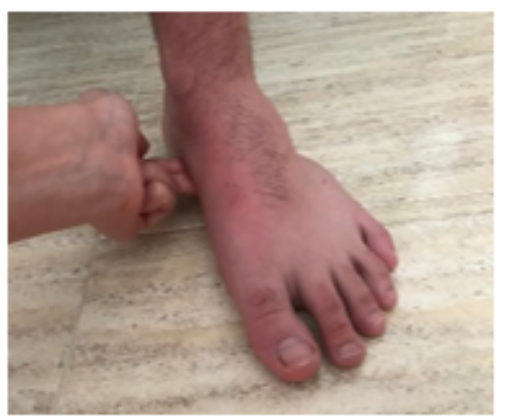

Figure 2: Supination resistance test.

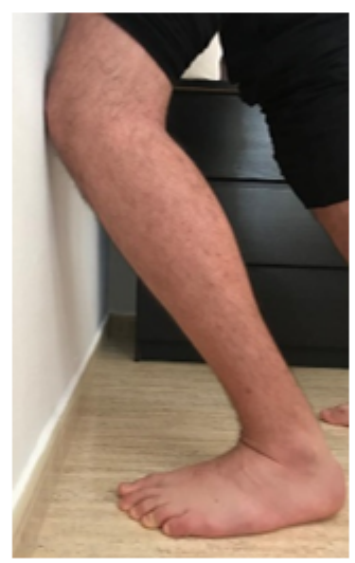

Figure 3: Lunge's test.

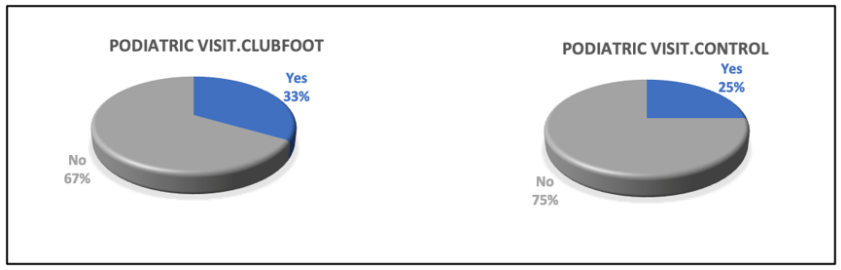

Figure 4: Podiatric visit in both groups.

In addition, patients were asked if they used at any time insoles or orthopaedically adapted shoes.

All patients were also submitted to a Podiatrists evaluation: The maximum pronation test is used to measure foot pronation range and it determines if the foot is functioning maximally pronated [22], while the supination resistance test estimates the amount of external pronation forces applied during the load situations [23]. Lunge's test measures talocrural dorsiflexion range of motion [24]. This measurement is done with a double arm goniometer. The FPI is a method of rating foot posture in the three plans [25].

\section{Results}

The clubfoot group whose values were registered in table 1, had a mean age at beginning of treatment of 15 days, $55,8 \%$ of 
Is the Quality of Life, Functionality and Podiatric Evaluation of Adolescents with Clubfoot Treated by Ponseti Method Worse than that of Other Adolescents?

patients have bilateral affection, the correction was obtained with an average of 6,25 cast (from 5 To 7) and 83.3\% needed tenotomy for equinus deformity (Table 1 ).
The SF-36 shows similar results between the CTEV group and the control group, no statistically significant difference $(p<0,05)$. CTEV group presents better general results, except for the subscale

\begin{tabular}{|l|c|c|c|c|c|c|}
\hline Group & Mean age & $\begin{array}{c}\text { Age beginning of } \\
\text { treatment }\end{array}$ & Affected side & $\begin{array}{c}\text { Number of } \\
\text { casts }\end{array}$ & Initial tenotomy & $\begin{array}{c}\text { Transposition of the } \\
\text { anterior tibial tendon }\end{array}$ \\
\hline 12 & $17,3+/-4,1$ years & 15 days & $\begin{array}{c}\text { Bilateral: } 7(58.33 \%) \\
\text { Right: } 4(33.33 \%) \\
\text { Left: } 1(8.33 \%)\end{array}$ & 6.25 & $\begin{array}{c}\text { Yes: } 10(83.33 \%) \\
\text { No: } 2(16.66 \%)\end{array}$ \\
\hline
\end{tabular}

Table 1: Clubfeet patients data.

of physical function, pain and general health as opposing to all the other values that are better in CTEV patients (Graph 1 and table 2).

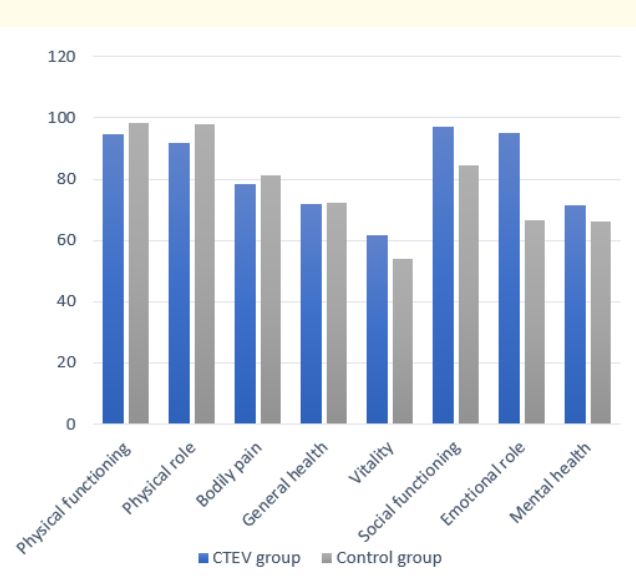

Graph 1: Diagram of Evaluation in SF36 between affected and control patients (punctuation in vertical axis).

\begin{tabular}{|l|c|c|}
\hline & CTEV group & Control group \\
\hline Physical functioning & $94.58^{*}$ & 93.83 \\
\hline Physical role & 91.67 & 97.92 \\
\hline Bodily pain & 78.56 & 81.46 \\
\hline General health & 72.08 & 72.50 \\
\hline Vitality & $61.67^{*}$ & 54.17 \\
\hline Social functioning & $97.29^{*}$ & 84.38 \\
\hline Emotional role & $94.44^{*}$ & 66.67 \\
\hline Mental health & $71.47^{*}$ & 66.33 \\
\hline Result & $78.83^{*}$ & 72.56 \\
\hline
\end{tabular}

Table 2: SF36 Punctuation - $\left({ }^{*}\right.$ marked those where Ponseti treated patients are better).
In the analysis of the Laaveg-Ponseti test, $58.33 \%$ of the 12 CTEV patients showed an excellent result, 41,67\% were good and nobody was between fair and bad (Table 3).

\begin{tabular}{|l|c|}
\hline \multicolumn{1}{|c|}{ Punctuation } & CTEV group \\
\hline Excellent $(90-100)$ & 7 \\
\hline Good $(80-89)$ & 5 \\
\hline Fair $(70-79)$ & 0 \\
\hline Bad $(>70)$ & 0 \\
\hline
\end{tabular}

Table 3: Laveeg-Ponseti in clubfoot patients.

Concerning podiatric visit, when the patients CTEV were asked if they had been to the podiatry for study or to apply plantar supports or silicone orthotics, only 4 patients answered yes, while 8 answered no. In control group the incidence of podiatric consultation was 25\%, 3 adolescents over 12 (Figure 4). Three of the 4 patients that had been to the podiatry in clubfoot group (75\%) had recurred and they received a Transposition of the anterior tibial tendon.

Podiatric evaluation results

In the maximum pronation test out of 19 clubfeet evaluated, 4 obtained a negative result, while the remaining 15 were positive. In control group only 2 adolescents ( 4 over 24 feet) obtained negative results (Figure 5). This test doesn't show statistically significant differences between the two groups.

In the supination resistance test 5 out of 19 clubfeet evaluated obtained negative results, while the remaining 14 were positive. In control group the results show an opposite tendency with just 4 feet of 24 get positive values (Figure 6). 


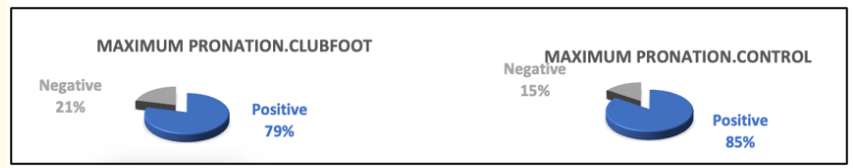

Figure 5: Maximum pronation test in both groups.

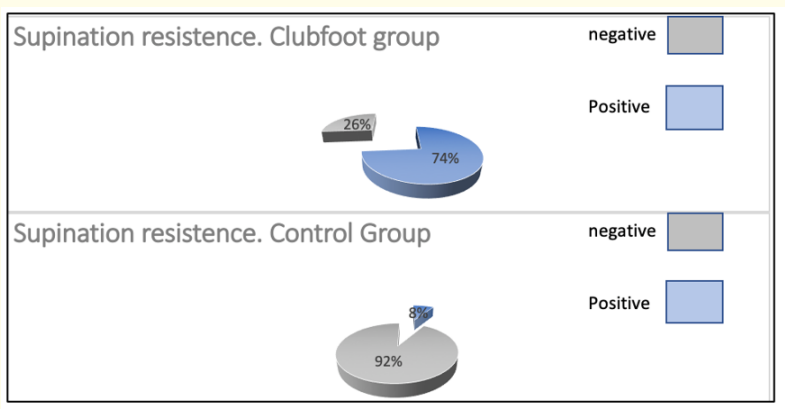

Figure 6: Supination resistance test in both groups.

Although everyone in Clubfoot group got a result over $0^{\circ}$ in the Lunge test, there was a limited dorsal flexion rate in all members of Clubfoot Group, with an average of $12^{\circ}$. In Control group the average dorsal flexion was $31,8^{\circ}$, just one of control group members was considered as pathological (Figure 7).

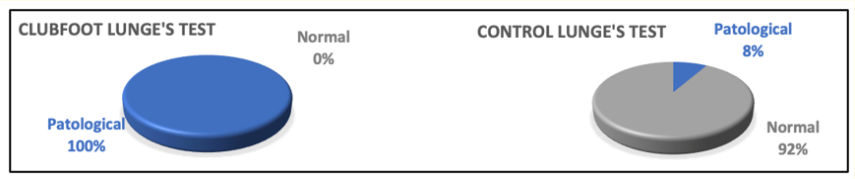

Figure 7: Lunge's test in both groups.

The Foot Posture Index identified that 5 out of 6 feet that were under a transposition of the anterior tibial tendon were neutral and one was in pronation, while the remaining 13 were in supination posture. The 5 non affected feet of this Group were in neutral position. As it is shown in graph 2, only one member of Control Group was in supination posture, the others were neutral or in pronation.

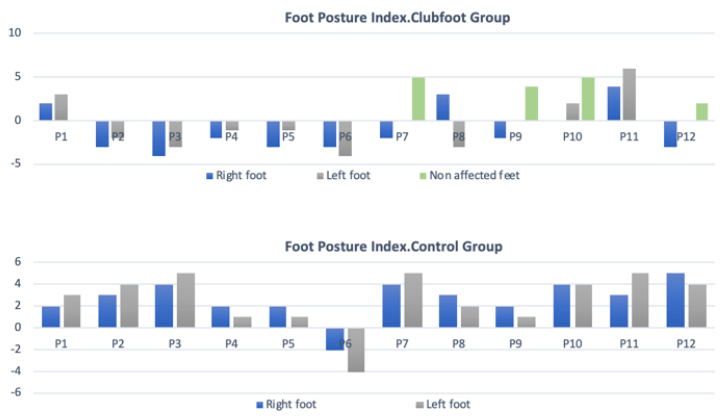

Graph 2: Foot posture index in both groups.

The obtained results in Clubfoot group and Control Group with Supination Resistance Test, Lunge's Test and Foot Posture Index have clear differences and the statistical analysis is significant ( $p$ $<0.005$ ).

\section{Discussion}

There is an extensive bibliography on Clubfoot treatment and the Ponseti method is currently considered the most accepted and effective method. However, the studies that analyse the patient long-term quality of life are insufficient and for this reason this study was undertaken.

After a research and review of available papers documenting the treatment of clubfoot, only 20 papers treated clubfoot and quality of life and just one has a control group. The number of cases in those papers are from 26 to 123 patients but ages vary from 2 weeks to 27 years and just one paper consider all patients older than 18 years.

In our study during the Laaveg-Ponseti test, $58.33 \%$ of the results were excellent and $41,67 \%$ were good, while nobody was between fair and bad. These results are very similar to $\mathrm{M}$. Porchea [26], A.J.F.G. Chueire [27] and P.R. Cock [28] results, where the excellent and good results reported were 89.29\%, 96\% y 94\% respectively. Whilst the results obtained in this paper were better in comparison with the ones showed by I. Ponseti [16] and F.R. Dietz [29], where the total of excellent and good results were $74 \%$ y $80 \%$ respectively, it should be noted that the Dietz paper is a thirty years follow-up evaluation period in comparison to the shorter period of 
the M. Porchea [26], A.J.F.G. Chueire [27] and P.R. Cock [28] and the age can be a factor of influence in changes in functionality.

According to M.B. Dobbs research, according to the established parameters of the Laaveg-Ponseti test aggressive surgical treatment of CTEV patients, t resulted in the following: (67\%) fair and bad, with a total of 33\% excellent and good [30] this paper has demonstrated definitively the difference between being or not being operated (surgical releases) for the future of patients quality of life and functionality.

We consider that the minimal difference between the affected group and the control group during the SF-36 questionnaire (better in CETV patients) is related more to the adolescence period than to the deformity over the childhood as a precursor/for future problems. If we compare with the study of F.R. Dietz [29], physical component is the only factor higher in the control group, on the other hand the control group and the CTEV group have an equal emotional value, while in our study the emotional evaluation is minimally worse in control group (Table 2).

According to M.B. Dobbs group evaluated with SF-36 the physical results are lower than the demographic average results. However, in the mental parameters the results are equivalent. In addition, the patients treated with extensive surgical interventions obtain similar physical results to the patients with radiculopathy, patients ongoing haemodialysis or patients with chronic heart failure [30].

The adolescents with clubfoot obtained different results in all podiatric tests compared to non-affected group, specifically in Supination Resistance Test, Lunge's Test and Foot Posture Index. This results show that despite Ponseti Method allow a normal function and quality of life there are structural and muscle function differences in clubfeet that are associated to the congenital malformation and we can detect them by X-ray or MRN, or we can consider some podiatric test as a sensible method of monitoring these patients outcome. The podiatric evaluation can be an added tool to assist orthopaedic paediatric surgeons in following up and to detecting any alarm signs, and as has been showed in our results.

Concerning podiatric treatment, only 4 patients had been to the podiatrist and 3 out of 4 experienced a recurrence. The podiatric evaluation can be an added tool to assist orthopaedic paediatric surgeons in following up and to detecting any alarm signs.
Possibly the role of the podiatrist in a multidisciplinary group for CTEV treatment and monitoring has not been established yet. But after this results in terms of podiatric evaluation it is acceptable to consider that podiatrist can be part of an interdisciplinary Clubfoot approach.

The main limitation of this study is the number of clubfeet evaluated (19 feet).

Otherwise, this is one of few papers that compared 2 groups over 18 y.o. and the first one that includes podiatric evaluation. And for an ideal future study, it would be necessary to re-evaluate the patients in ten years; in the same way that Dobbs [30] made in order to demonstrate that the good functionality and good quality of life persists over time, contrary to cases with extensive surgical interventions.

This approach could be extended by performing a study in order to analyse the static and dynamic landing in order to assess the distribution of pressure.

\section{Conclusion}

The function and quality of life of a CTEV patient treated properly by Ponseti Method is equivalent to most adolescents without pathology.

In referring to the proposed objectives:

1. The functionality after the Ponseti treatment evaluated with Laaveg-Ponseti scale is excellent or good in $100 \%$ of patients.

2. After evaluating the quality of life of the CTEV adolescent older than 18 years old treated by Ponseti Method it is possible to conclude that this treatment does not reduce the quality of life during adolescence.

3. The podiatric evaluation Clubfoot Patients Group show differences compared to Control group, reflecting the structural changes in clubfeet.

4. The role of a podiatrist in the monitoring and treatment of clubfoot is not yet established, although its inclusion in the multidisciplinary team is important.

\section{Bibliography}

1. Johansson A., et al. "Range of motion in the talo - navicular and the calcaneo - cuboid joints evaluated by ultrasound dur- 
ing clubfoot treatment with normal references to the age of four years". Journal of Children's Orthopaedics 12.5 (2018): 526-538.

2. Owen RM and Kembhavi G. "A critical review of interventions for clubfoot in low and middle-income countries: Effectiveness and contextual influences". Journal of Pediatric Orthopaedics Part B 21.1 (2012): 59-67.

3. Ey AM. "Tratamiento del pie equinovaro congénito". Revista Del Pie Y Tobillo 31.1 (2017): 3-14.

4. Ponseti IV. "Treatment of congenital club foot Concepts Review Treatment of Congenital". The Journal of Bone and Joint Surgery American 74 (1992): 448-454.

5. Zionts KE., et al. "The influence of sex and laterality on clubfoot severity". Journal of Pediatric Orthopaedics (2015): 1-5.

6. Pavone V., et al. "The etiology of idiopathic congenital talipes equinovarus: A systematic review". Journal of Orthopaedic Surgery and Research 13.1 (2018): 1-11.

7. Dobbs MB and Gurnett CA. "Update on clubfoot: Etiology and treatment". Clinical Orthopaedics and Related Research 467.5 (2009): 1146-1153.

8. Weymouth KS., et al. "Functional assessment of clubfoot associated with HOXA9, TPM1 and TPM2 variants suggests a potential gene regulation mechanism". Clinical Orthopaedics and Related Research 474.7 (2016): 1726-1735.

9. Engell V., et al. "Heritability of clubfoot: a twinstudy". Journal of Children's Orthopaedics 8 (2014): 37-41.

10. Chu A., et al. "Clubfoot classification: correlation with Ponseti cast treatment". Journal of Pediatric Orthopaedics 30.7 (2010): 695-699.

11. Gao R., et al. "Correlation of Pirani and Dimeglio scores with number of Ponseti cast required for clubfoot correction". Journal of Pediatric Orthopaedics 34.6 (2014): 639-642.

12. Jochymek J., et al. "Classification systems to evaluate the clubfoot and their potential use to predict the course and the results of the Ponseti method treatment". Acta chirurgiae orthopaedicae et traumatologiae Cechoslovaca 85.5 (2018): 331335.
13. Ponseti I V and Smoley EN. "The classic: Congenital club foot: The results of treatment". Clinical Orthopaedics and Related Research 467.5 (2009): 1133-1145.

14. O'Shea RM and Sabatini CS. "What is new in idiopathic clubfoot?" Current Reviews in Musculoskeletal Medicine 9.4 (2016): 470-477.

15. Ponseti IV., et al. "Pie Zambo: El Método de Ponseti. 3ra. Edition: Global - HELP Organization (2003).

16. Ponseti IV. "Long - Term Results of Treatment of Congenital Club Foot". Journal of Bone and Joint Surgery 62-A (1980): 2331.

17. Sherbourne CD. "The MOS 36 - ítem short - form health survey (SF - 36). Conceptual framework and ítem selection". Medical Care 30.6 (1992): 473-483.

18. Madariaga IA. "Aspectos estadísticos del Cuestionario de Calidad de Vida relacionada con salud Short Form 50.167 (2008): 147-192.

19. Fuentes A., et al. "Valoración funcional y de calidad de vida en pacientes tratados con artrodesis de tobillo". Trauma 21.2 (2010): 102-110.

20. Alonso J., et al. "La versión española del SF-36 Health Survey (Cuestionario de Salud SF-36): un instrumento para la medida de los resultados clínicos". Journal Medical and Clinical 104 (1995): 771-776.

21. Alonso J., et al. "Valores poblacionales de referencia de la versión española del Cuestionario de Salud SF-36". Journal Medical and Clinical 111 (1998): 410-416.

22. Pascual Huerta J. "Pie plano, 2o parte. Podomorfos: Boletín Informativo del Colegio Oficial de Podólogos de Canarias (2008): 17-25.

23. García Campos J., et al. “¿Es el test de pronación máxima fiable?" Revista Española de Podología 1 (2012): 6-8.

24. Alfaro Santafé JJ., et al. "Resultados del test de Lunge en pacientes con hallux limitus funcional: estudio transversal de casos y controles". Revista Española de Podología 28.2 (2017): 87-92. 
25. Abad E., et al. "The Foot Posture Index. Análisis y revision". El Peu 31.4 (2011): 190-197.

26. Porchea MM., et al. "Mid - term results of Ponseti method for the treatment of congenital idiopathic clubfoot - (A study of 67 clubfeet with mean five year follow - up)". Journal of Orthopaedic Surgery and Research 6 (2011): 3.

27. Chueire AJFG., et al. "Treatment of congenital clubfoot using Ponseti method". Revista Brasileira de Ortopedia (2016).

28. Cock PR., et al. "Resultados del tratamiento de pie equinovaro congénito con el método de Ponseti". Colombian Journal of Orthopedics and Traumatology (2018).

29. Dietz FR., et al. "Long - term Results of Comprehensive Clubfoot Release Versus the Ponseti Method: Which Is Better?" Clinical Orthopaedics and Related Research 472.4 (2014): 1281-1290.

30. Dobbs MB., et al. "Long-term follow-up of patients with clubfeet treated with extensive soft-tissue release". Journal of Bone and Joint Surgery American 88 (2006): 986-996.

\section{Volume 4 Issue 9 September 2021}

(C) All rights are reserved by Ey Batlle Ana Maria., et al. 